\title{
A walk in the park
}

\author{
Is Pokémon Go foreshadowing the future of biodiversity research and scientific outreach?
}

\author{
David Roy Smith
}

O n Saturday mornings, I like to fill my travel mug with three shots of espresso and take a stroll through Gibbons Park, which is down the road from my apartment in London, Ontario. In winter, when the park is deep in snow, I often see cross-country skiers, sledders, and hardy dog walkers. In summer, when the flowers are out, I know to be on the lookout for speedy cyclists, sweaty joggers, and runaway toddlers. But the other day on my morning meandering, I came across something unexpected: numerous small and scattered gatherings of people, young, and old, all staring intently at their smartphones.

cc

... my beloved park had

become a PokéStop and my

quiet contemplative morning

was now a victim of

Pokémania."

At first, I thought it was some sort of public scavenger hunt or a community garbage pickup with more texting than picking going on. But listening to the iPhone itinerants quickly solved the riddle. "Quick", shouted a young girl, "there's a Bulbasaur in that big tree". "Yes", screamed a middleaged father, "I finally caught a Zubat". "I can't believe it”, cried an older woman by a swing set, "I’ve wasted three Poké Balls on a Doduo!” Then and there I realized the problem: My beloved park had become a PokéStop and my quiet contemplative morning was now a victim of Pokémania.

\section{Hunting critters}

As almost everyone on Earth now knows, Pokémon Go is a free-to-play game for mobile devices, which blends virtual reality with the real world (Fig 1D). Users download the app, create an avatar, and then hit the streets trying to find and catch a wide diversity of fictional Pokémon species, from Magikarp, which lives by bodies of water, to Sandshrew, which frequents deserts and other hot spots. According to Apple, Pokémon Go has broken the App Store record for the most first-week downloads and has attracted millions of gamers from more than thirty countries worldwide.

As the morning progressed, I sat at a picnic table, sipped my coffee, and watched the Pokémon addicts at work. Despite the disturbance to my routine, I was impressed that a smartphone app could entice so many people away from their air-conditioned havens into the natural world. Normally, Gibbons Park is quite empty, but now I could see a group of kids by the river and another group trekking through the long grass behind the tennis courts. There was an entire family gazing up the trunk of my favorite tree and a young girl with her shoes off wading through the duck pond. Even more remarkably, all of these people were on the hunt for biodiversity, which filled my biologist's heart with joy, until I remembered that they were not interested in bona fide biodiversity but only the imaginary type.

Indeed, when a great blue heron landed ten feet away from the players by the river none of them noticed or looked up from their smartphones. But, of course, herons do not give "Stardust", "Candies", or any other kinds of Pokémon points. The group in the long grass trampled over flowers and small bushes and was indifferent to the scattering of birds and squirrels in their wake. And the girl in the pond inadvertently separated a brood of ducklings from their mother. There has also been widespread media coverage about how some Pokémon players are becoming a public nuisance as well as warnings about how the game can bring children into contact with strangers. But rather than dwelling on the negatives, I focused on the positives, on the fact that so many young people were outside on a beautiful day, and on the massive potential that exists for engaging the public in the natural world through online games.

\section{The power of online games}

A few years ago, I sat in on a talk by Professor Paul Hebert, a biologist at the University of Guelph, Canada, who is passionate about genetic barcoding and cataloging life's diversity. Toward the end of the talk, Paul gave the audience a vision of the future- - a future where biologists can identify, inventory, and measure biodiversity in the field, in real time, and in a few minutes. Paul predicted the creation of an iPhone-sized handheld device that could isolate DNA, amplify and sequence a barcode region, and then run a molecular sequence alignment and a phylogenetic analysis, allowing the user to correctly identify organisms.

CC

... I was impressed that a smartphone app could entice so many people away from their air-conditioned havens into the natural world."

Watching the Pokémon Go players scouring the park for digital critters with their smartphones reminded me of Paul's vision. I began to imagine that instead of tracking Poké monsters my fellow park goers were out en masse capturing genetic diversity. 

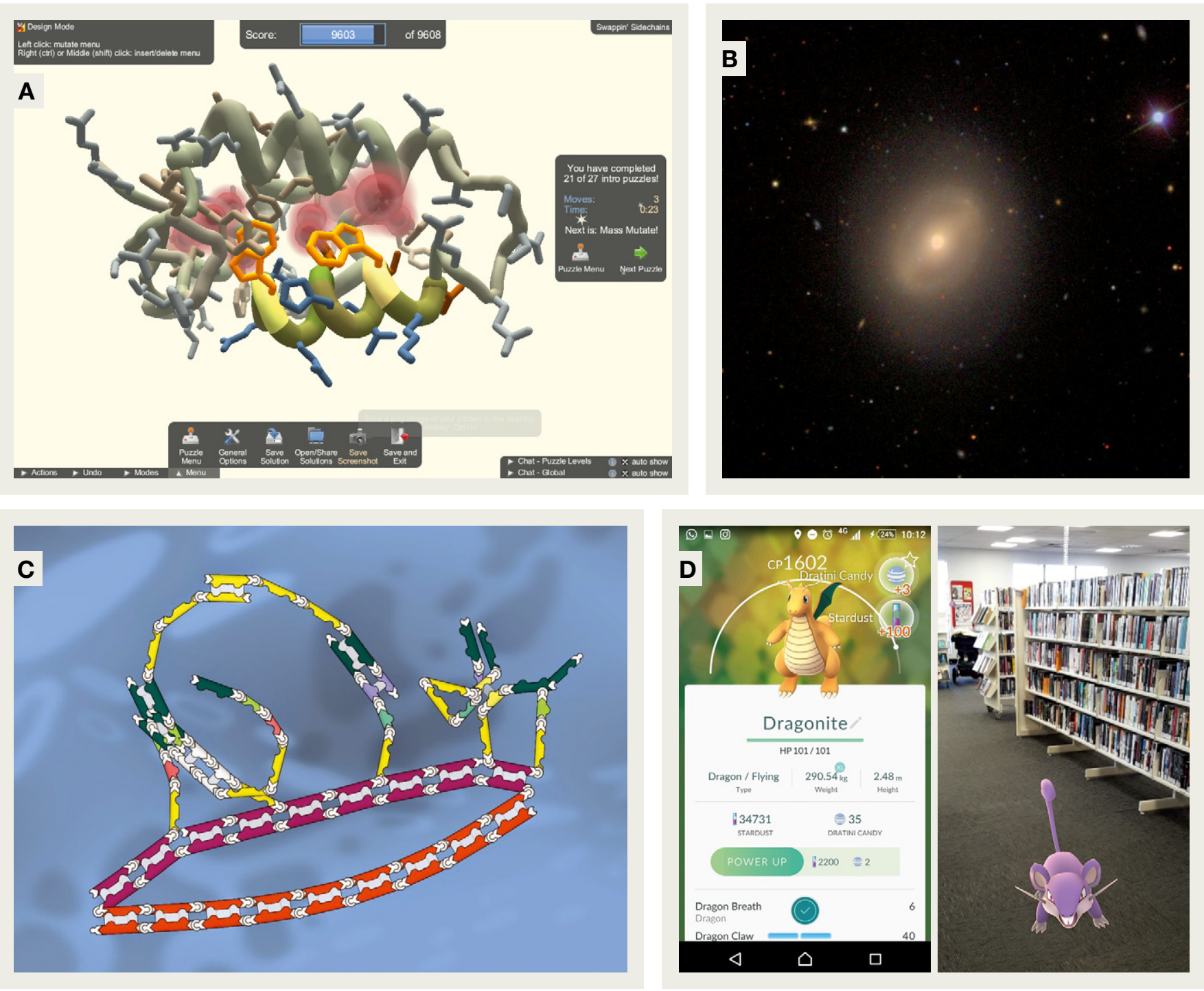

Figure 1. Screenshots of online games.

(A) Foldit (https://fold.it); (B) Galaxy Zoo (www.galaxyzoo.org); (C) Nanocrafter (http://nanocrafter.org/); (D) Pokémon Go.

I could almost hear the excitement: "Hey, mom", hollers a little boy, "I got a new subspecies of hymenoptera". "My goodness", says one teenager to another, "look at the polymorphisms in the cox 1 gene from that critter!" As hard as it is to envision kids getting enthusiastic about barcoding, any undergraduate genetics teacher can tell you how excited students get when looking at data they generated, especially DNA sequences.

We have not yet reached the age of the handheld genetic analyzer, but we are arguably not far off. With every passing day, DNA sequencing machines are getting faster, smaller, and more efficient. Massive amounts of DNA sequencing data can now be generated from a single cell in only a few hours. And hundreds of high-end, userfriendly bioinformatics programs exist for quickly assembling, aligning, and analyzing these data [1]. It is only a matter of time before these kinds of technologies are put in the hands (and handheld devices) of the scientific masses, meaning that they could be used to stimulate a Pokémon Go-style of scientific and educational outreach.

\section{A zoo of citizen science projects}

Various online tools have been surprisingly successful at engaging the public with science. For example, crowdfunding platforms such as Kickstarter, Indiegogo, and
Experiment have raised millions of dollars for research and helped launch a range of scientific discovery programs and environmental protection endeavors [2]. The citizen science platform Zooniverse (https:// www.zooniverse.org), which is run by the Citizen Science Alliance (CSA), employs the brainpower-and in some cases computing power-from hundreds of thousands of volunteers (referred to as Zooites) to help researchers process and interpret a deluge of data they are inundated with [3].

Originally launched in 2009, Zooniverse now boasts more than 1.4 million registered users who can freely participate in dozens of different research projects, ranging from the Frozen Forests Project, in which participants 
identify giant kelp through Landsat satellite images, to the Worm Watch Project, in which users track the egg-laying behavior of nematodes by watching online videos. For space geeks, Zooniverse offers Galaxy Zoo (Fig 1B), an astronomy project where volunteers scan images of outer space and classify galaxies according to their shapes. As a protistologist, it is no surprise that my favorite part of Zooniverse is Plankton Portal, which lets users identify and classify microbial life from underwater images.

\section{"Various online tools have been surprisingly successful at engaging the public with science"}

Much like Zooniverse, the Center for Game Science (CGS) at the University of Washington has built a variety of online scientific discovery games, including ones for STEM education and cognitive skills training. The game Nanocrafter (Fig 1C), for instance, allows players to construct devices with DNA, which aids in the advancement of synthetic biology [4]. One of the CGS's most popular games is Foldit (Fig 1A), which uses crowdsourcing to build better proteins. After a short tutorial, users are given real proteins to digitally fold into bizarre conformations and are awarded points based on the properties and possible function of their folded products [5].

Engaging the public in science is a laudable endeavor, but are initiatives such as Foldit and Zooniverse and their armies of citizen scientists actually helping advance science and answer important research questions? The answer is yes. As of January 2016, the work of citizen scientist volunteers at Galaxy Zoo has contributed to the publication of nearly 50 scientific papers, and some users have even had galaxy clusters named after them-the Matorny-Terentev Cluster RGZ-CL J0823.2+0333 is named after the two Zooites who pieced together its structure [6]. Similarly, a survey of results from the Zooniverse project Cell Slider-in which users score images of tumor cores from breast cancer-found that citizen scientists were almost as good as trained pathologists in spotting cancerous cells [7].

After failing to accurately solve the crystal structure of monomeric retroviral protease, scientists challenged Foldit users to model the protein. Remarkably, the players "were able to generate models of sufficient quality for successful molecular replacement and subsequent structure determination" [8]. The list of effective citizen science projects goes on and on, and research suggests that participation in online science initiatives improves science learning: "more actively engaged participants perform better in a project-specific science knowledge quiz, even after controlling for their general science knowledge" [9]. In fact, there is no reason why the future of citizen science cannot look like and be as successful as Pokémon Go. But some new forms of science engagement are forfeiting the smartphone and online component and taking their cues from old-fashioned games-an approach that is surprisingly effective.

"

"... the work of citizen scientist volunteers at Galaxy Zoo has contributed to the publication of nearly, 50 scientific papers ..."

Long before Pokémon Go hit the App Store, there was another hugely popular Pokémon game, which was played with paper cards (in a dungeons and dragonstype fashion) instead of mobile devices. David Ng, Director of the Advanced Molecular Biology Laboratory at the University of British Columbia, built upon the success of Pokémon to engage young people in science and created a Pokémon-like card game called Phylo (http://phylogame.org), which is based on real creatures. For instance, the card for the North America Beaver, Castor canadensis, is worth 5 points-one point fewer than the card of HIV-I. Each card contains a description and a beautifully drawn image of the organism. What's more, the game takes a crowdsourcing approach, seeking input from scientists, game designers, and educators. Phylo, which launched in 2010 and currently boasts over 700 different cards, was inspired by a paper in Science [10] showing that some children knew more about Pokémon characters than they knew about the plants and animals in their own backyards. Perhaps it is time for David to design the Pokémon Go version of Phylo.

\section{Joining the fold}

When I got home from the park, I made a sandwich, read for an hour, and then downloaded Pokémon Go to my phone. Soon my apartment was full of cute monsters and I was tripping over chairs, coffee tables, and dirty laundry trying to catch them. Later that afternoon in the cereal aisle of my local grocery store, I was savoring the sweet sound of capturing a Rattata. It was obvious that the game is so appealing and addictive because it involved a mix of exploration, treasure hunting, and the real world, which are precisely the same reasons why I love scientific research. Perhaps the popularity of Pokémon Go is a sign that millions of people are eager to engage in citizen science-or at least craving hands-on interactions with the biological world. The challenge for scientists, educators, and developers is to design innovative tools, software, and games that can safely, productively, and sustainably harness these potential interests.

\section{"Perhaps the popularity of Pokémon Go is a sign that millions of people are eager to engage in citizen science-or at least craving hands-on interactions with the biological world."}

By the evening, my eyes were tired from staring at a small screen and my ears were ringing from the incessant beeping and background music. I shutdown the game, turned off the lights, and took refuge in the chirping of a red-breasted robin outside my bedroom window, in the rustling of maple leaves and rose bushes, in the purring of my pet cat on the pillow beside me, and in all of the wonderful things that make up the game of life.

\section{Acknowledgements}

DRS is supported by a Discovery Grant from the Natural Sciences and Engineering Research Council (NSERC) of Canada. He can be found online at www.arrogantgenome.com and (a)arrogantgenome.

\section{Conflict of interest}

The author declares that he has no conflict of interest 


\section{References}

1. Smith DR (2015) Buying in to bioinformatics: an introduction to commercial sequence analysis software. Brief Bioinform 16: $700-709$

2. Wheat RE, Wang Y, Byrnes JE, Ranganathan J (2013) Raising money for scientific research through crowdfunding. Trends Ecol Evol 28: $71-72$

3. Segal A, Gal YAK, Simpson RJ, Victoria Homsy V, Hartswood M, Page KR, Jirotka M (2015) Improving productivity in citizen science through controlled intervention. Paper presented at the Proceedings of the 24th International Conference on World Wide Web; 331-337 May 2015

4. Barone J, Bayer C, Copley R, Barlow N, Burns M, Rao S, Seelig G, Popovic Z, Cooper S
(2015) Nanocrafter: design and evaluation of a DNA nanotechnology game. Paper presented at the Proceedings of the 10th International Conference on the Foundations of Digital Games; June 2015

5. Khatib F, Cooper S, Tyka MD, Xu K, Makedon I, Popović Z, Baker D (2011) Algorithm discovery by protein folding game players. Proc Natl Acad Sci USA 108: 18949-18953

6. Banfield JK, Andernach H, Kapińska AD, Rudnick L, Hardcastle MJ, Cotter G, Vaughan S, Jones TW, Heywood I, Wing JD et al (2016) Radio Galaxy Zoo: discovery of a poor cluster through a giant wide-angle tail radio galaxy. Mon Not $R$ Astron Soc 462: $2376-2384$

7. dos Reis FJC, Lynn S, Ali HR, Eccles D, Hanby A, Provenzano E, Caldas C, Howat WJ,
McDuffus LA, Liu B et al (2015)

Crowdsourcing the general public for large scale molecular pathology studies in cancer. EBioMedicine 2: 679-687

8. Khatib F, DiMaio F, Cooper S, Kazmierczyk M, Gilski M, Krzywda S, Zabranska H, Pichova I, Thompson J, Popović Z et al (2011) Crystal structure of a monomeric retroviral protease solved by protein folding game players. Nat Struct Mol Biol 18: 1175-1177

9. Masters K, Oh EY, Cox J, Simmons B, Lintott C, Graham G, Greenhill A, Holmes K (2016) Science learning via participation in online citizen science. J Clin Outcomes Manag 15: A07

10. Balmford A, Clegg L, Coulson T, Taylor J (2002) Why conservationists should heed Pokémon. Science 295: 2367 